\title{
Fracture of the Radial Neck and Proximal Ulna with Medial Displacement of the Radial Shaft
}

\author{
N.K. Sferopoulos* \\ Department of Pediatric Orthopaedics, “G. Gennimatas” Hospital, Thessaloniki, Greece
}

*Corresponding Author: N. K. Sferopoulos, Department of Pediatric Orthopaedics, “G. Gennimatas” Hospital, Thessaloniki, Greece.Email: sferopoulos@yahoo.com, sferopoulos@in.gr

\begin{abstract}
The classification of proximal radial fractures into three major groups, according to Chambers, is based on the mechanism of injury and the displacement of the radial head. In the head-displaced fractures (group I) the radial head is primarily displaced. The two subclasses of fractures in group I are angular injuries and those associated with elbow dislocations. In the neck-displaced fractures (group II) the distal radial fragment is primarily displaced. Finally, stress injuries are included in group III. A child with a fracture of the radial neck and proximal ulna with complete medial displacement of the radial shaft is presented and the classification of the injury is discussed.
\end{abstract}

\section{EDITORIAL}

The fibrous articular capsule of the elbow joint attaches to the proximal third of the radial neck. Distally, the capsule protrudes under the annular ligament to form a cavity resembling a sac (recessus sacciformis). Thus, only a small portion of the neck lies within the articular capsule. Since most of the neck is extracapsular, fractures of the radial neck may not produce an intraarticular effusion and a positive fat pad sign. No ligaments are attached directly to the radial head or neck. The radial collateral ligament is attached to the annular ligament. Ossification of the proximal radial epiphysis begins at approximately 5 years of age as a small, flat nucleus. This ossific nucleus may originate as a small sphere or it can be bipartite, which is a normal variation and should not be misinterpreted as a fracture. The radial head is relatively stable and locked by the annular ligament. The immature radial head that is primarily cartilaginous absorbs the force and transmits it to the weaker physis or metaphysis of the neck [1-3]. In children and adolescents the intraarticular radial head fractures have a significantly lower incidence, compared with the extraarticular ones, but they are associated with a much higher rate of complications [4].

Chambers classification of the proximal radial fractures into three major groups is based on the mechanism of injury and the displacement of the radial head. In group I, which is the most common type of injury, the radial head is primarily displaced. In group II the distal radial fragment is primarily displaced. Finally, in group
III chronic repetitive stress injuries, due to both longitudinal and rotational forces on either the head or the proximal radial physis are included.

Group I fractures are divided in two subclasses including the valgus injuries or those associated with elbow dislocations. Valgus injuries are subdivided into three types based on the location of the fracture line. Type A includes Salter-Harris type I or II injuries, type B includes Salter-Harris type IV injuries and type $\mathrm{C}$ includes metaphyseal fractures with no involvement of the physis. Fractures associated with an elbow dislocation are subdivided into two types. The former occur during spontaneous reduction, while the latter occur during the process of dislocation of the elbow [5].

The most common mechanism of radial neck fractures involves a fall on the outstretched hand with the elbow extended. An associated valgus force to the forearm compresses the capitulum against the radial head. The cartilaginous head absorbs the force and transmits it to the weaker physis or metaphysis. This may produce an angular displacement of the neck. Further valgus forces may produce other concomitant injuries in the elbow region, such as a posterior dislocation of the elbow, an avulsion of the ulnar (medial) epicondyle, a rupture of the ulnar collateral ligament or capsule, and a fracture of the olecranon or of the proximal shaft of the ulna [68].

Most of the valgus force is usually concentrated in the distal portion of the olecranon. The 
periosteum in children is immature and thick, which may prevent the degree of separation that is usually detected in fractures of the olecranon in adults The larger amount of epiphyseal cartilage in children may serve as a cushion to lessen the effects of a direct blow to the olecranon. The metaphyseal cortex is relatively thin, allowing for the development of angulated greenstick extraarticular fracture lines. In addition, the fracture line may occasionally extend distally to the coronoid process or to the proximal ulnar shaft region, due to the distal localization of the fulcrum of the bending force $[9,10]$.

Patterson believed that once the stabilizing effect of the radial head is lost, the distal fragment (radial neck and proximal shaft) may migrate proximally. This proximal migration of the distal fragment tends to be ulnarward because of the unopposed muscle pull by the supinator and biceps muscles. He also described a manipulative technique attempting to counteract these forces. When there is a strong valgus component, the proximal portion of the distal fragment of the radius may get locked medially to the coronoid process, making a closed reduction almost impossible $[9,11]$.

Group II fractures include a primary disruption or deformity of the neck, while the head remains congruous within the proximal radioulnar joint. They may be due to torsional or angular forces. Therefore, two subgroups of the neck-displaced fractures involving either the torsional or the angular injuries have been described $[2,5,9,12$ $15]$.

Torsional (rotational) forces may fracture the radial neck in young preschool-aged children before the appearance of the ossification centre of the proximal radial epiphysis. There are only two reported cases of this rare injury in the European literature. In both of them the initial rotational force was in supination, while reduction was achieved by pronation of the forearm. Differential diagnosis from the much more common subluxation of the radial head, also known as pulled elbow or nursemaid's elbow, is extremely difficult. History and clinical findings may be confusing. Signs of hemarthrosis are usually evident on the radiographs in the torsional fractures, but not in the pulled elbow syndrome. In addition, ultrasonography, arthrography or an examination under general anesthesia may occasionally be required to diagnose a torsional fracture [16-20].
Angular forces to the forearm in varus following a fall on the outstretched hand with the elbow extended may cause a Monteggia type III injury including a greenstick fracture of the olecranon or proximal ulna and a lateral dislocation of the radial head. However, the failure may occasionally occur at the radial neck (Monteggia III equivalent). The radial neck displaces laterally, leaving the radial head and proximal neck fragment in anatomic position under the annular ligament. Placing the forearm in supination results in the apex being anterior; therefore, anterior pressure on the proximal radial shaft with the arm in supination reduces the shaft to the radial head [21-23].

The first description of a fracture of the radial neck that was associated with medial displacement of the shaft of the radius was made by Manoli [24] and was followed by Fogarty [25]. In both cases the radial shaft was displaced medially to the coronoid process and was locked in that position. A diagnosis of anterior dislocation of the proximal fragment was also made intraoperatively. Both authors have used the term dislocation to describe the severe tilting or rotation, as well as the translocation or complete separation of the proximal radial fragment [26]. The head of the radius is considered as completely displaced when no contact with the rim of the metaphysis exists [27].

These lesions are obviously classified as group I injuries that are due to angular forces producing a valgus deformity after a fall on the extended elbow. Once the stabilizing effect of the radial head is lost the application of further forces in valgus may lead to a secondary displacement of the distal fragment ulnarward and proximally. Attempts at closed reduction may fail due to the locking of the distal fragment to the coronoid process of the ulna.

It may be reasonable that the valgus stress pattern may cause associated injuries about the elbow. However, an association with a proximal fracture of the ulna has only been presented in two reports thereafter. Strong et al. [28] reported two children with fractures of the radial neck and medial displacement of the radial shaft. In both cases a long oblique greenstick fracture of the proximal ulna was also diagnosed. The radial head was dislocated anteriorly as well. The most recent case was reported by Dillon and King [29] who indicated that their case was irreducible by closed means, requiring open reduction and internal fixation. 
We have treated at our institution a single case with a fracture of the radial neck and proximal ulna with medial displacement of the radial shaft.

A 10-year-old boy injured his elbow after a slip while running. Radiographs indicated a displaced Salter-Harris type II fracture of the proximal radial physis. There was total medial displacement of the shaft of the radius that was locked medially to the coronoid process. An undisplaced fracture of the olecranon was also diagnosed (Fig. 1). The radial fracture was irreducible by closed means and was treated with open reduction and internal fixation. Open reduction was performed under general anesthesia through a lateral (Boyd) approach. When the joint was opened, the radial head was found to be rotated and tilted. The distal fragment was freed from the tightly surrounding muscles. The periosteum of the distal fragment was split longitudinally and reflected throughout the circumference of bone, with a smooth and curved periosteal elevator, for a distance sufficient to insert around the distal fragment two mini Hohmann retractors. The radial diaphysis was then manipulated with the retractors laterally and reduced. The fracture was fixed with a transcapitellar K-wire. Uneventful healing of the fractures was recorded 6 months later.

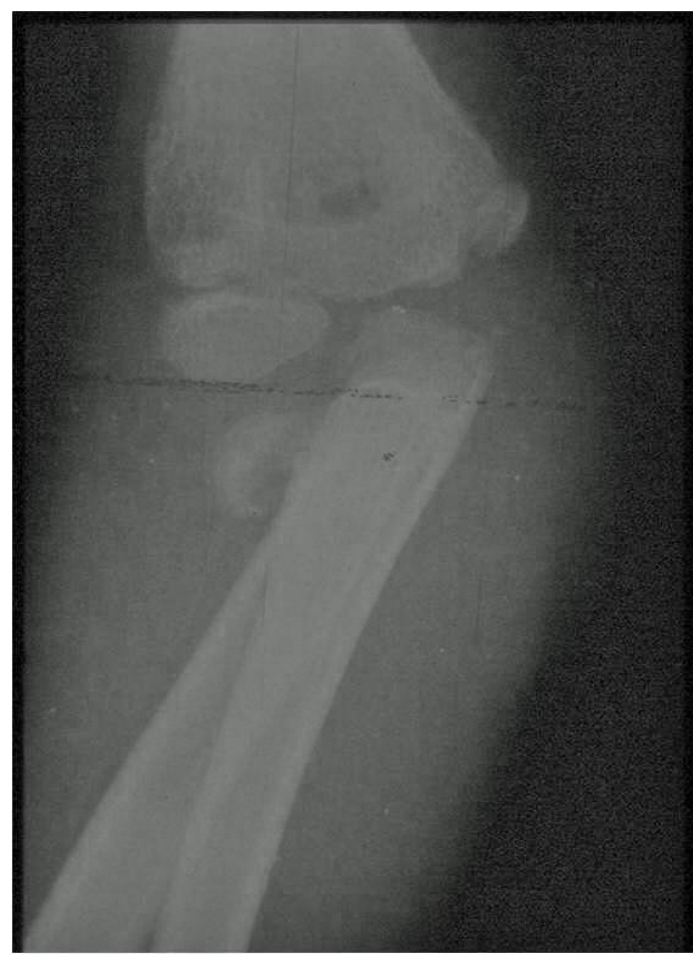

Figure1. Radiographs of the left elbow showed a displaced fracture of the radial neck and an undisplaced fracture of the olecranon. The distal radial fragment was completely displaced medially.

\section{REFERENCES}

[1] Mitra S. Anatomy. Academic Publishers, Calcutta, 2006.

[2] Erickson M, Garg S. Chapter 13: Radial neck and olecranon fractures. In: Flynn JM, David L. Skaggs DL, Waters PM (eds). Rockwood and Wilkins': Fractures in children. $8^{\text {th }}$ ed. Wolters Kluwer Health, Philadelphia, 2015.

[3] Singh V. Textbook of anatomy upper limb and thorax; Volume 1. $3^{\text {rd }}$ ed. Elsevier, 2018.

[4] Ackerson R, Nguyen A, Carry PM, Pritchard B, Hadley-Miller N, Scott F. Intra-articular radial head fractures in the skeletally immature patient: Complications and management. J Pediatr Orthop. 2015; 35(5): 443-8.

[5] Chambers HG. Fractures of the proximal radius and ulna. In: Kasser JR, Beaty JH, eds. Rockwood and Wilkins': Fractures in children. $5^{\text {th }}$ ed. Lippincott Williams \& Wilkins, Philadelphia, 2001.

[6] Jeffery CC. Fractures of the head of the radius in children. J Bone Joint Surg Br. 1950; 32: 31424.

[7] Vahvanen V, Gripenberg L. Fracture of the radial neck in children. A long-term follow-up study of 43 cases. Acta Orthop Scand. 1978; 49(1): 32-8.

[8] Radomisli TE, Rosen AL. Controversies regarding radial neck fractures in children. Clin Orthop Relat Res. 1998; 353: 30-9.

[9] Erikson M, Frick S. Fractures of the proximal radius and ulna. In: Kasser JR, Beaty JH, eds. Rockwood and Wilkins': Fractures in children. Volume $3.7^{\text {th }}$ ed. Lippincott Williams \& Wilkins, Philadelphia, 2010.

[10] Vostal O. Fracture of the neck of the radius in children. Acta Chir Orthop Traumatol Cech. 1970; 37: 294-301.

[11] Patterson RF. Treatment of displaced transverse fractures of the neck of the radius in children. $\mathrm{J}$ Bone Joint Surg. 1934; 16: 695-8.

[12] Ogden JA. Skeletal injury in the child. Springer, New York, 2000.

[13] Peterson HA. Epiphyseal growth plate fractures. Springer-Verlag, Berlin Heidelberg, 2007.

[14] Herring JA. Tachdjian's Pediatric Orthopaedics: From the Texas Scottish Rite Hospital for Children. $5^{\text {th }}$ ed. Elsevier Saunders, Philadelphia, 2014.

[15] Mencio GA, Swiontkowski MF. Green's skeletal trauma in children. $5^{\text {th }}$ ed. Elsevier Saunders, Philadelphia, 2015.

[16] Henrikson B. Isolated fractures of the proximal end of the radius in children epidemiology, treatment and prognosis. Acta Orthop Scand. 1969; 40(2): 246-60.

[17] Gille P, Mourot M, Aubert D, Lecuyer F, Djebar A. Fracture of the neck of the radius. Rev Chir Orthop Reparatrice Appar Mot. 1978; 64(3): 247-8. 
[18] Dohi D. Confirmed specific ultrasonographic findings of pulled elbow. J Pediatr Orthop. 2013; 33(8): 829-31.

[19] Lee YS, Sohn YD, Oh YT. New, specific ultrasonographic findings for the diagnosis of pulled elbow. Clin Exp Emerg Med. 2014; 1(2): 109-13.

[20] Bexkens R, Washburn FJ, Eygendaal D, van den Bekerom MP, Oh LS. Effectiveness of reduction maneuvers in the treatment of nursemaid's elbow: A systematic review and meta-analysis. Am J Emerg Med. 2017; 35(1): 159-63.

[21] Olney BW, Menelaus MB. Monteggia and equivalent lesions in childhood. J Pediatr Orthop. 1989; 9: 219-23.

[22] Kaufman B, Rinott MG, Tanzman M. Closed reduction of fractures of the proximal radius in children. J Bone Joint Surg Br. 1989; 71(1): 667.

[23] Monson R, Black B, Reed M. A new closed reduction technique for the treatment of radial neck fractures in children. J Pediatr Orthop. 2009; 29: 243-7.
[24] Manoli A 2nd. Medial displacement of the shaft of the radius with a fracture of the radial neck. Report of a case. J Bone Joint Surg Am. 1979; 61(5): 788-9.

[25] Fogarty EE, Blake NS, Regan BF. Fracture of the radial neck with medial displacement of the shaft of the radius. Br J Radiol. 1983; 56: 4867.

[26] Lindham S, Hugosson C. The significance of associated lesions including dislocation in fractures of the neck of the radius in children. Acta Orthop Scand. 1979; 50(1): 79-83.

[27] Falciglia F, Giordano M, Aulisa AG, Di Lazzaro A, Guzzanti V. Radial neck fractures in children: results when open reduction is indicated. $\mathbf{J}$ Pediatr Orthop. 2014; 34(8): 756-62.

[28] Strong ML, Kropp M, Gillespie R. Fracture of the radial neck and proximal ulna with medial displacement of the radial shaft. Report of two cases. Orthopedics. 1989; 12(12): 1577-9.

[29] Dillon MT, King JC. Irreducible radial neck fracture in a child. J Surg Orthop Adv. 2006; 15(2): 90-4.

Citation: N. K. Sferopoulos. Fracture of the Radial Neck and Proximal Ulna with Medial Displacement of the Radial Shaft. ARC Journal of Orthopedics. 2019; 4(1):1-4. doi:dx.doi.org/ 10.20431/2456-0588.0401001.

Copyright: (C) 2019 Authors. This is an open-access article distributed under the terms of the Creative Commons Attribution License, which permits unrestricted use, distribution, and reproduction in any medium, provided the original author and source are credited. 